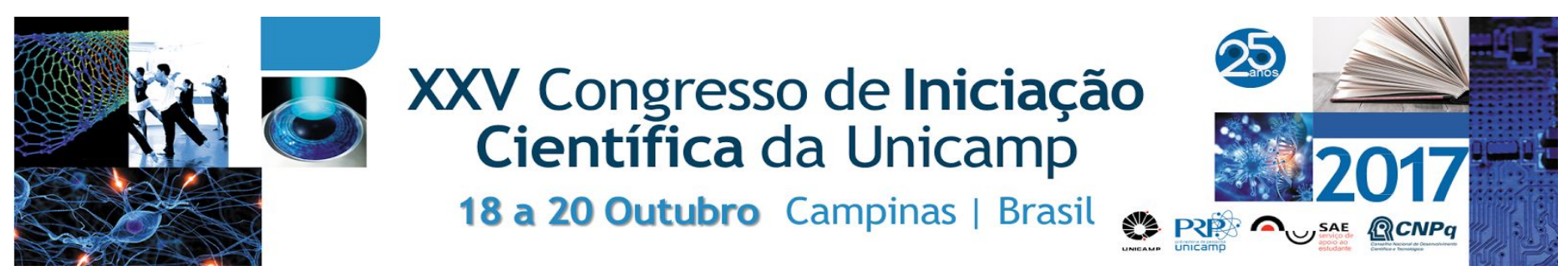

\title{
Estudos tafonômicos e morfológicos de braquiópodes do intervalo Ordoviciano-Siluriano e Devoniano da Bacia do Paraná.
}

\section{Debora Liemi Tanji*, Isabela Marques, Kauana Cristina Mazzarelli da Silva, Carolina Zabini.}

\section{Resumo}

A Tafonomia é o estudo dos processos biológicos e geológicos relacionados à formação dos fósseis. A Taxonomia, por sua vez, é responsável pelo reconhecimento e nomenclatura de espécies. Neste trabalho, apresentamos alguns dos projetos atuais do laboratório de Paleohidrogeologia da Unicamp. Em todos buscamos associar a tafonomia e morfologia dos braquiópodes com o paleoambiente (de vida e de morte) e, assim, procuramos entender relações paleoecológicas e condições paleoambientais vigentes nos processos formadores dos fósseis em questão.

\section{Palavras-chave:}

Paleontologia de Invertebrados, Tafonomia, Brachiopoda

\section{Introdução}

O termo Tafonomia tem origem grega (tafos=sepultamento, nomos=leis) e refere-se a uma área da paleontologia destinada a desvendar processos relacionados à formação dos fósseis.

Após a morte de um organismo, diversos fatores, tanto biológicos quanto geológicos, afetarão a forma como este será ou não preservado [1]. Ao analisarmos um fóssil, podemos, a partir da avaliação de suas características (intrínsecas) ou daquilo que o cerca (preservadas nas rochas), obter informações sobre o ambiente, as formas de vida dos organismos presentes em uma amostra, e as causas de sua morte e de sua fossilização.

A Taxonomia (do grego, taxo=organização, nomia=método) é um campo da ciência, componente da sistemática, na qual há a classificação, identificação, descrição e nomenclatura dos organismos. A partir da taxonomia é possível estabelecer as nomenclaturas e reconher as espécies.

A Tafonomia e a Taxonomia, embora tenham nomes muito semelhantes, possuem enfoques muito diferentes. A Tafonomia necessita da Taxonomia, pois é importante que se conheça as espécies que se estuda. Por outro lado, a Taxonomia nos fósseis é baseada em morfologia, que pode ser alterada pelos processos tafonômicos.

\section{Resultados e Discussão}

Em nossos trabalhos, analisamos fósseis de braquiópodes (lingulídeos e discinídeos) coletados em diferentes formações geológicas da Bacia Sedimentar do Paraná.

No afloramento da formação lapó e Vila Maria, (Ordoviciano-Siluriano), analisamos 9 níveis estratigráficos. Observamos a distribuição de valvas de braquiópodes discinídeos entre os níveis, o seu nível de fragmentação (Pequena, Média ou Grande), tamanho, tipo
(Braquial ou Pedicular), número de linhas de crescimento e tipo de fossilização (Substituição, Impressão, Molde interno). Com isso objetiva-se reconhecer processos de transporte e seleção de material durante a preservação.

Neste mesmo afloramento, é possível visualizar a existência de dois grupos de braquiópodes morfologicamente muito semelhantes quando jovens, mas com formas adultas distintas. Afim de testar se essas diferenças morfológicas entre os indivíduos jovens são significativas, fotografamos e coletamos dados morfométricos (número de linhas de crescimento, comprimento dorso-ventral e ântero-posterior, ângulo das linhas de crescimento em relação ao eixo dorso-ventral e ao eixo ântero-posterior, por exemplo). Os dados estatísticos apontam uma diferença significativa entre os grupos, em suas formas jovens, contribuindo para o conhecimento da paleobiodiversidade pretérita.

Já com os fósseis da formação Ponta Grossa (Devoniano) estudam-se as possíveis relações paleoecológicas preservadas nas valvas de lingulídeos. Pretende-se com isso levantar hipóteses acerca dos fatores de formação de tais perfurações.

\section{Conclusões}

Através desses estudos, procuramos associar a tafonomia e morfologia dos braquiópodes ao seu paleoambiente e compreender melhor as condições vigentes durante a vida e após a morte dos organismos estudados.

1. CARVALHO ID. Paleontologia: Conceitos e Métodos. 3aed. Vol. 1. Editora Interciências. 2010. 